\title{
Neural mechanisms involved in the detection of our first name: a combined ERPs and PET study
}

\author{
Fabien Perrin ${ }^{(1),(2)}$, Pierre Maquet ${ }^{(1)}$, Philippe Peigneux ${ }^{(1)}$, Perrine Ruby ${ }^{(1)}$, Christian Degueldre ${ }^{(1)}$, Evelyne \\ Balteau $^{(1)}$, Guy Del Fiore ${ }^{(1)}$, Gustave Moonen ${ }^{(3)}$, André Luxen ${ }^{(1)}$, Steven Laureys ${ }^{(1)}$ \\ ${ }^{a}$ Centre de Recherches du Cyclotron, Université de Liège, Belgique \\ ${ }^{\mathrm{b}}$ Laboratoire de Neurosciences and Systèmes Sensoriels, Université Claude Bernard Lyon 1,
}

CNRS-UMR 5020, 50 Av T. Garnier, 69366 Lyon Cedex 07, France

${ }^{\mathrm{c}}$ Service de Neurologie, Université de Liège, Belgique

\begin{abstract}
In everyday social interactions, hearing our own first name captures our attention and gives rise to a sense of self-awareness, since it is one of the most socially self related stimulus. In the present study, we combined ERPs and PET scan methods to explore the cerebral mechanisms underlying the detection of our own name. While categorical analyses of PET data failed to reveal significant results, we found that the amplitude of the P3 component, elicited when hearing one's own name, correlates with regional cerebral blood changes in right superior temporal sulcus, precuneus and medial prefrontal cortex. Additionally, the latter was more correlated to the P3 obtained for the subject's name compared to that obtained for other first names. These results suggest that the medial prefrontal cortex plays the most prominent role in self-processing.
\end{abstract}

Keywords: Medial prefrontal cortex; P3; Self-processing

\section{Introduction}

Our own first name is intrinsically meaningful for each of us because of its personal significance, its emotional content and repetition along life. Beyond our day-to-day experience, the extreme salience of one's own first name was highlighted in various experimental and clinical studies. Moray's (1959) early studyofthe 'cocktail party' phenomenon has shown that approximately one-third of the subjects report hearing their own name in an unattended auditory channel, while none of them could recall the details of the unattended speech (see also Wood \& Cowan, 1995). This suggests that the subject's own name (SON) is so potent that it could "capture attention and subsequently bring that stimulus into awareness" (Mack, Pappas, Silverman, \& Gay, 2002). The powerful detection of the SON in comparison with other stimuli was also shown in situations of reduced consciousness. For example, it has been shown that the presentation of the SON during sleep could evoke behavioural responses (Oswald, Taylor, \& Treisman, 1960), as well as a differential brain electrical response associated to its discrimination (Perrin, García-Larrea, Mauguière, \& Bastuji, 1999; Perrin, Bastuji, Mauguière, \& García-Larrea, 2000; Pratt, Berlad, \& Lavie, 1999). Behavioural responses were demonstrated in 4-5 months old babies, who are able to recognise the sound patterns of their own names (Mandel, Jusczyk, \& Pisoni, 1995). Robust responses were also found in demented patients whose perception of their own name deteriorated well after perception of time, place and recognition (Fishback, 1977). At last, after general anaesthesia, reactivity to the SON occurs first, before reactivity to pain or to a noise (Kurtz et al., 1977), and its presentation in comatose patients increases the chances of obtaining differential brain responses associated to information processing (Signorino, D’Acunto, Angeleri, \& Pietropaoli, 1995).

The neural correlates of the discrimination of the SON have not been yet properly investigated. However, some anatomical hypotheses may be put forward, since hearing our first name elicits a self-experience, i.e. a "consciousness of oneself as an immediate subject of experience, unextended in time" (Gallagher, 2000; for a review see Kircher \& David, 2003). This stimulus is of particular interest in the study of self-processing because 
its detection is associated with an enhancement of self-awareness. Since it is used by the others to directly refer to ourself, the SON plays an important part in our everyday social interactions. For this reason, it can be considered as a very ecological and highly socially self-related stimulus. Prior neuroimaging studies identified several cortical structures involved in various self-processing: the medial prefrontal cortex (MPFC) and/or the anterior cingulate cortex, the right temporo-parietal junction and the precuneus. For instance, MPFC could be involved in tasks where subjects have to make a self-referential judgement (Gusnard, Akbudak, Shulman, \& Raichle, 2001; Lane, Fink, Chau, \& Dolan, 1997) and in tasks requiring (self-)reflection on their personal abilities, traits or attitudes (Johnson et al., 2002; Kelley et al., 2000, 2002; Kircher et al., 2001; Kjaer, Nowak, \& Lou, 2002). Activation of all three regions have been described in studies where subjects were implicated in a narrative history, i.e. when they had to take a first-person or a self-perspective (Vogeleyetal., 2001; Vogeley \& Fink, 2003). At last, both MPFC and precuneus were reported to be activated in the conscious resting state (Mazoyer et al., 2001; Raichle et al., 2001), i.e. in a condition where subjects paid their attention towards various internal processes. Even if the resting state is considered by some authors as a behaviourally ill-defined heterogeneous condition, other suggested that it is "the ultimate state of inspection of the self" (Wicker, Ruby, Royet, \& Fonlupt, 2003).

The aim of the present study was to identify the cerebral mechanisms underlying the capacity to discriminate our first name in the external world. We investigated the P3 (or P300) potential, for which the parietal component (the 'P3b') is enhanced when subjects detect an implicit target stimulus such as the SON, even in the absence of any explicit instruction (Berlad \& Pratt, 1995; Folmer \& Yingling, 1997; Perrin et al., 1999). We focused our attention on the parietal P3 wave since its amplitude is sensitive to both task relevance (the SON is particularly relevant and inherently attended) and stimulus probability, thus may reflect the information-processing resources allocated to the categorisation/discrimination of the SON (for a review, see Picton, 1992). Furthermore, we simultaneously acquired positron emission tomography (PET) images in the aim to identify brain regions in which regional cerebral blood flow changes correlated with the P3 amplitude to the SON, i.e. brain areas which were specifically modulated when the resources allocated to detection of the SON changed.

\section{Methods}

\subsection{Subjects}

Fifteen right-handed (Edinburgh Inventory, Oldfield, 1971) healthy volunteers (five women, $22.7 \pm 3$ years) without hearing deficit and without medical, neurological, nor psychiatric history participated to the study. The experiment was conducted in agreement with the guidelines of the 'Declaration of Helsinki' and was approved by the Ethics Committee of the Faculty of Medicine of the University of Liège. Written informed consent was obtained from all subjects. All subjects had a disyllabic first name, which was non-commonly used in French language (i.e. employed less than 30,000 times in France during the 20th century: see http://www.prenoms.com/, Kilos Mutimedia Sarl, IDDN.FR.010.0077897.000.R.P.2000.028.40000).

\subsection{Stimuli}

Three types of auditory stimuli were used: the subject's own name (SON), uncommon first names (UFN), and common first names (CFN, i.e. employed more than 300,000 times during the 20th century).

The experimental material was constructed using a $2 \times 2$ factorial design, where the type of stimuli (SON versus UFN) and the probability of occurrence of the first name (20\% versus $50 \%)$ were independently manipulated. (We did not include a high SON occurrence condition since it would induce a habituation effect and preclude P300 and related rCBF measurements.) We elaborated four conditions, of 48-60 stimuli, containing:

(1) SON with a probability of occurrence of $20 \%$ and four CFN with a probability of $20 \%$ each [labelled "S20"];

(2) $\mathrm{SON}$ at $50 \%$ and four $\mathrm{CFN}$ at $12.5 \%$ each [labelled "S50"];

(3) UFN at $20 \%$ and four CFN at $20 \%$ each[labelled "U20"];

(4) UFN at $50 \%$ and four CFN at $12.5 \%$ each [labelled "U50"]. 
The probability of occurrence of the three types of stimuli was the same within the entire sequence and within the 90 -s period of PET scanning.

The UFN were the first names of the other participants. Twelve first names were used as CFN and randomly presented across conditions, series and subjects; they were the same for all participants. Thus, the group comparison of two conditions eliminated the acoustical effect of all first names. Moreover, prior to the experiment a list of the five most employed first names, of relatives and friends, was obtained from each subject and eliminated from the lists.

Each condition was repeated three times and was randomly presented across subjects. Within each series, first names were pseudo-randomly presented. SOA was $2000 \mathrm{~ms}$. All first names were recorded by the same neutral male voice, digitised and replayed binaurally at about $80 \mathrm{~dB}$ SPL maximal intensity with Cogent software environment (Wellcome Department of Imaging Neuroscience, London, UK,

http://www.vislab.ucl.ac.uk/Cogent/). All were disyllabic and had a maximum length of $600 \mathrm{~ms}$.

Subjects were instructed to listen passively and to remain attentive to the stimuli all along the recording session. We did not use an active attention task in the aim to further apply this protocol in subjects with altered states of consciousness (such as coma, general anaesthesia, sleep, dementia, minimally conscious state, etc.).

\subsection{ERPs, PET and MRI acquisitions}

Electroencephalographic (EEG) signals from nine $\mathrm{AgCl}$ electrodes (Fz, Cz, Pz, F3, C3, P3, F4, C4, P4), placed according to the International 10-20 system (Jasper, 1958; Klem, Lüders, Jasper, \& Elger, 1999) and referenced to the nose, electrooculogram (EOG) from two electrodes diagonally above and below the right eye, and electrocardiogram (ECG) from two electrodes on pectoral muscles, were amplified $(150,000 \mathrm{x})$ and sampled at $1000 \mathrm{~Hz}$ by a Synamps acquisition system connected to a Neuroscan (NeuroSoft, Sterling, VA, USA) equipment, with an analog bandpass of 0.1-70 Hz. A ground electrode was placed near Fpz and impedance was kept below $5 \mathrm{k} \Omega$.

After the installation of the electrodes, the subject was installed on the (PET) scanner couch. Her/his head was stabilised by a thermoplastic facemask. A venous catheter was inserted in a left anterobrachial vein and two earphones were inserted into the external acoustic canals. PET data were acquired on a CTI 951 R 16/31 scanner in three-dimensional mode (Siemens, Erlangen, Germany). Cerebral blood flow was estimated while subjects listened to names in one of the four conditions. Each scan consisted of two frames: a 30-s background frame and a 90 -s frame. The slow intravenous water $\left(\mathrm{H}_{2}{ }^{15} \mathrm{O}\right)$ infusion begun just before the second frame. Six millicurie (222 MBq) were injected for each scan. The infusion was totally automated. Data were reconstructed using a Hanning filter (cut-off frequency 0.5 cycle/pixel) and corrected for attenuation and background activity.

Structural T1-weighted MRI scans were obtained by an Allegra 3 T MR (Siemens, Erlangen, Germany) at a [0.9 $\mathrm{mm}$ x $0.9 \mathrm{~mm}$ x $0.9 \mathrm{~mm}$ ] voxel size (MPRAGE, TR $=1960 \mathrm{~ms}$, TE $=4.43 \mathrm{~ms}, \mathrm{FA}=8^{\circ}$ ).

\subsection{ERPs data analyses}

The EEG analysis was conducted on the stimuli presented during PET scanning (i.e. the 90-s frame). Individual event-related potentials (ERPs) were analysed over a $1700 \mathrm{~ms}$ epoch, including a prestimulus baseline of 200 $\mathrm{ms}$, and averaged according to the condition (S20, S50, U20, and U50), the type of stimulus (SON or UFN and $\mathrm{CFN}$ ) and the electrode position. Prior to averaging, single epochs containing eye movement or muscular artefact with amplitude exceeding $\pm 50 \mu \mathrm{V}$ were excluded from the average. Then, ERPs were averaged across subjects and digitally filtered between 0.1 and $30 \mathrm{~Hz}$ (roll off: $24 \mathrm{~dB} /$ oct.) to create grand-averaged ERPs (used for illustrative purposes). Statistical computations were performed on averaged traces from each individual: amplitudes (from baseline) and latencies of the N1, P2, N2 and P3 components were calculated for each individual average. These values were tested with a three-way analysis of variance (ANOVA) with repeated measures on the type of first names (SON or UFN versus CFN), the condition (S20 versus S50 versus U20 versus U50) and the electrode position (Fz versus $\mathrm{Cz}$ versus $\mathrm{Pz}$ ). Post-hoc Bonferroni tests were performed when significant interactions emerged on ANOVA.

The difference in P3 amplitude between the SON or the UFN and the CFN was calculated for each individual average at its maximum, i.e. at $\mathrm{Pz}$, and these values were used as covariate of interest in the subsequent SPM analyses. 
Separate ANOVAs were performed to test the existence of laterality effects on the P300 under our experimental conditions. P300 amplitudes were submitted to similar repeated measurements ANOVAs than described above, but using lateral temporal electrodes (T3 and T4) as levels for the 'electrode position' factor. For all analyses, no significant effect nor interactions were noted for the electrode side factor, and therefore further analyses were restricted to midline electrodes in order to maximise the P300 effect, which is known to predominate over the midline.

\subsection{PET data analyses}

PET data were analysed using the statistical parametric mapping software SPM99 (Wellcome Department of Cognitive Neurology, London, UK, http://www.fil.ion. ucl.ac.uk/spm/) implemented in MATLAB (Mathworks, Sherborn, MA). For each subject, all scans were realigned together, normalised and smoothed using a Gaussian kernel of 16-mm full width at half maximum.

The scan condition, covariate (P3), condition by covariate interaction and subject effects were estimated according to the general linear model (only one design matrix was constructed). Changes in global CBF were taken into account by a subjects specific ANCOVA. Areas of significant changes were determined using linear contrasts of condition estimates.

We first assessed the main effects of first name presentation independently of the probability of occurrence $[(\mathrm{S} 20-\mathrm{U} 20)+(\mathrm{S} 50-\mathrm{U} 50)$ and $(\mathrm{U} 20-\mathrm{S} 20)+(\mathrm{U} 50-\mathrm{S} 50)]$, those of the probability of occurrence independently of the type of first name $[(\mathrm{S} 50-\mathrm{S} 20)+(\mathrm{U} 50-\mathrm{U} 20)$ and $(\mathrm{S} 20-\mathrm{S} 50)+(\mathrm{U} 20-\mathrm{U} 50)]$ and the interactions between factors. Then, we looked for the simple effects of the type of first name (SON or UFN) at each probability of occurrence (S20-U20, S50-U50, U20-S20 and U50-S50).

Furthermore, we looked for the brain areas that covaried with the P3 amplitude obtained when subjects heard their own first name (SON) or an uncommon first name (UFN) at both probabilities of occurrence (S20 + S50 andU20 +U50). We also looked for the brain areas that were more correlated to the $\mathrm{P} 3$ amplitude obtained for the SON than that obtained for the UFN $[(\mathrm{S} 20+\mathrm{S} 50)-(\mathrm{U} 20+\mathrm{U} 50)]$.

The resulting set of voxel values for each contrast constituted a map of the t statistic, SPM (T), thresholded at $P($ uncorrected $) \leq 0.001$. Results were considered significant at $P<0.05$ after a small volume correction of 10 $\mathrm{mm}$ radius-sphere centred on the predetermined regions of interest. The latter were the medial prefrontal cortex (stereotaxic coordinates $x= \pm 6, y=54, z=11$, averaged coordinates taken from Gusnardetal., 2001; Johnson etal., 2002; Kelley et al., 2002; Lane et al., 1997; Mazoyer et al., 2001; Raichle et al., 2001; Vogeley et al., 2001), the right temporo-parietal junction $(x=58, y=-56, z=28$, Kjaer et al., 2002; Vogeley et al., 2001) and the precuneus ( $x= \pm 6, y=-52, z=45$, Kelley et al., 2002; Kircher et al., 2000, 2002; Kjaer et al., 2002; Johnson et al., 2002; Mazoyer et al., 2001; Raichle et al., 2001; Vogeley et al., 2001). Functional results were positioned on the averaged structural MRI of our subjects.

\section{Results}

\subsection{ERPs data}

Four event-related potentials were recorded to first name stimuli and labelled N1, P2, N2 and P3 (Fig. 1). They respectively peaked at about 110, 200, 280 and $400 \mathrm{~ms}$. ANOVA failed to demonstrate any significant difference in N1, P2 or N2 amplitudes or latencies between stimuli names in any condition.

Conversely, ANOVA showed that the electrode position had a significant effect on P3 amplitude $(F(2,28)=64$, $P=0.000000)$ reflecting its maximal scalp distribution over Pz site (Fig. 1). Furthermore, the analysis demonstrated that the type of first names, the condition and their interaction had significant effects on P3 amplitude (respectively $F(3,42)=5.30, P=0.003 ; F(1,14)=50.17, P=0.000005 ; F(3,42)=5.58, P=0.003$ ). Post-hoc analyses revealed that P3 amplitude was significantly greater when presenting the subjects' own first name (SON) than when presenting the common first names (CFN) in the S20 and S50 conditions $(P<0.005$ for both analyses), but that there was no P3 difference in amplitude between the uncommon first names (UFN) and the CFN in the U20 and U50 conditions $(P>0.05)$. 
S20

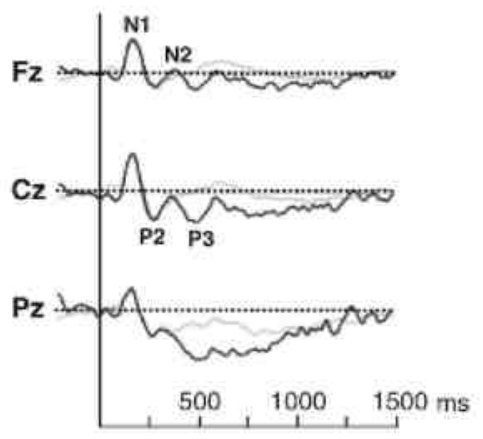

S50

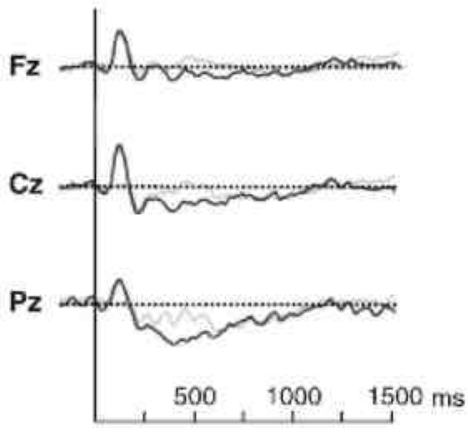

$5 \mu \mathrm{V} \frac{\bar{T}}{+}$

U20

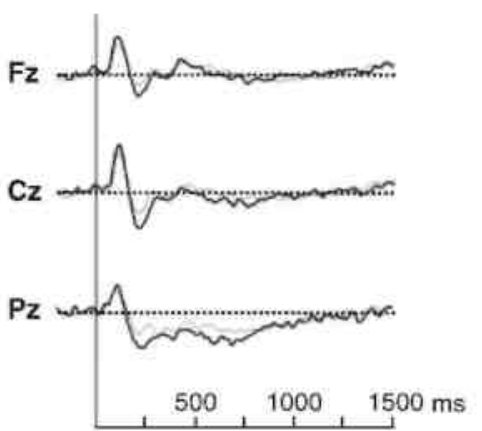

U50

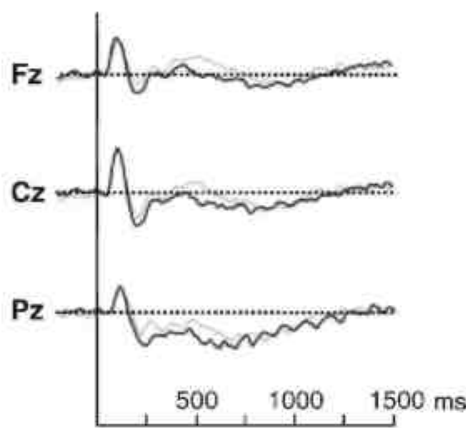

Fig. 1. Grand-averaged auditory evoked potentials of 15 subjects to hearing their own name (SON: thick traces) or an uncommon first name (UFN: thick traces) and to the other first names (CFN: thin traces) in the four conditions: S20 (when SON had a probability of 20\% and CFN of 20\%), S50 (when SON at $50 \%$ and CFN at $12.5 \%$ ), U20 (when UFN at $20 \%$ and CFN at $20 \%$ ) and U50 (when UFN at $50 \%$ and CFN at $12.5 \%$ ). Traces of the two types of names are represented at $\mathrm{Fz}, \mathrm{Cz}$ and $\mathrm{Pz}$.

Table 1: Brain areas where rCBF was linearly correlated to the P3 response evoked by hearing one's own first name The last line corresponds to the brain area which is more correlated to the P3 response obtained for the subject's own name than that obtained for another first name (x,y and $z$ are coordinates in the standard Talairach and Tournoux (1988) stereotactic space).

\begin{tabular}{|c|c|c|c|c|c|c|}
\hline Region & Brodmann area & $x(\mathrm{~mm})$ & $y(\mathrm{~mm})$ & $z(\mathrm{~mm})$ & $Z$ value & $\begin{array}{l}\text { Small volume corrected } P \text { - } \\
\text { value }\end{array}$ \\
\hline $\begin{array}{l}\text { Right medial prefrontal } \\
\text { cortex }\end{array}$ & 10 & 8 & 64 & 12 & 3.66 & 0.006 \\
\hline Left precuneus & 7 & -6 & -66 & 48 & 3.17 & 0.023 \\
\hline $\begin{array}{l}\text { Right superior temporal } \\
\text { sulcus }\end{array}$ & 39 & 64 & -58 & 28 & 3.16 & 0.023 \\
\hline $\begin{array}{l}\text { Right medial frontal } \\
\text { cortex }\end{array}$ & 10 & 8 & 64 & 16 & 3.88 & 0.003 \\
\hline
\end{tabular}




\subsection{PET data}

\subsubsection{Effects of the type of name and of the probability of occurrence}

Categorical comparisons based on the stimulus type (SON versus UFN) or its probability of occurrence (20\% versus $50 \%$ ) failed to reveal significant effects in regions of interest (even after a small volume correction centred on the predetermined regions of interest). These analyses did not include the electrophysiological measures. Thus, it could be suggested that PET data alone are less adapted to assess the brain responses to sparse events, as in the passive detection of the SON (in particular with our protocol in which similar conditions, except for one stimulus, were contrasted).

\subsubsection{Areas varying with the $\mathrm{P} 3$ amplitude}

The SPM analysis looking for brain areas that showed a linear correlation between $\mathrm{CBF}$ and the amplitude of the P3 responses identified four clusters: right medial prefrontal cortex, left precuneus, right superior temporal sulcus and right intraparietal sulcus ( $P$ (uncorrected $)<0.001$; the search volume the whole brain). Given that the right intraparietal sulcus $(x=34, y=-66, z=22)$ was not part of our a priori hypotheses, it is only reported for completeness but will not be discussed further. The three other regions corresponded to the a priori selected brain areas, which were predicted to participate to the discrimination of the SON. They were found significantly activated (see Table 1), at $P<0.05$ after a small volume correction, when we looked for the regions in which regional cerebral blood flow $(\mathrm{rCBF})$ covaried with the $\mathrm{P} 3$ at both probabilities of occurrence $(\mathrm{S} 20+\mathrm{S} 50)$. This analysis revealed significant linear regressions $(\rho>0.5, P<0.05)$ between the P3 values obtained in these two conditions and $\mathrm{rCBF}$ in the right medial prefrontal cortex (Fig. 2a), the right posterior end of the superior temporal sulcus (Fig. 2b), near the temporo-parietal junction (when superimposing on individual MRI, the activation was in the angular gyrus for three subjects), and the left precuneus (Fig. 2c).

Finally, the condition [(S20 + S50) versus (U20 + U50)] by covariate (P3 amplitude) interaction identified the medial prefrontal cortex as the only brain area where the response to the P3 was significantly larger for the SON than for the UFN.

No correlations between P3 values and any brain region was observed for UFN. 
(a)
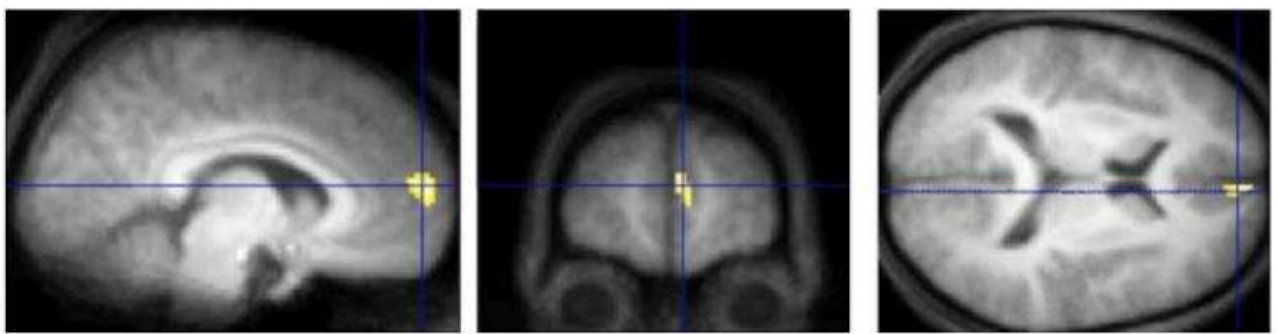

(b)
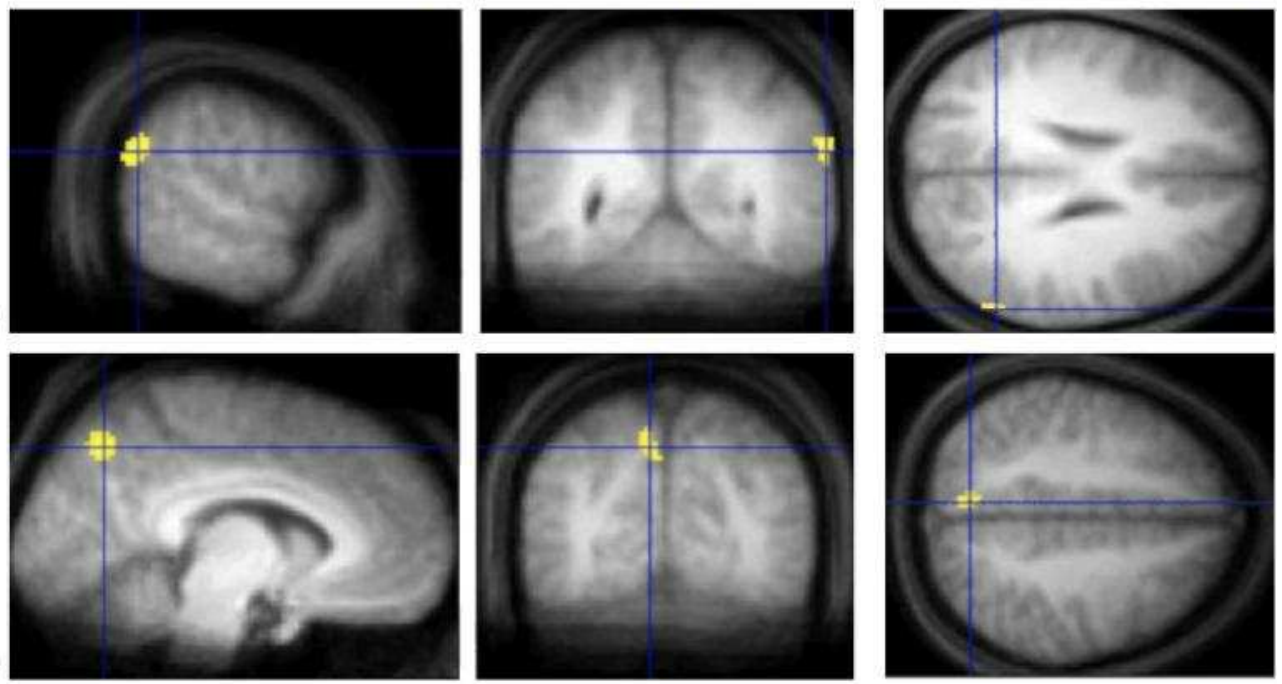

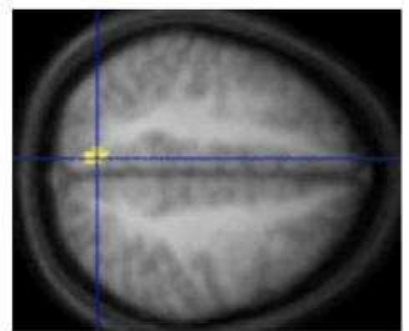

Fig. 2. Cerebral areas where $\mathrm{CCBF}$ showed a significant correlation with P3 amplitude when subjects heard their own first name: (a) the right medial prefrontal cortex, (b) the right posterior ending of the superior temporal sulcus, and (c) the left precuneus $(P<0.05$, corrected at the voxel level).

\section{Discussion}

The present study was designed to identify the brain areas that were involved in the detection of the subject's own name (SON), i.e. a word that induces a self-referential process, independently of its probability of occurrence in the series. The introduction of a sensible electrophysiological correlate of the identification of one's own first name, i.e. the P3 component, allowed us to identify the brain structures which are modulated when the resources allocated to the discrimination of the SON changed ${ }^{1}$.

First, a linear regression between $\mathrm{P} 3$ amplitude and regional cerebral blood flow (rCBF) changes was observed in the right medial prefrontal cortex (MPFC) when subjects heard sequences containing their own first name. This activation is consistent with neuropsychological studies, which showed that impairments of self-awareness or self-reflection, as well as incapacity to reflect on personal knowledge, occur more frequently following medial prefrontal damage than other regions (Ackerly \& Benton, 1947; Damasio, Trenel, \& Damasio, 1990; Stuss, 1991; Wheeler, Stuss, \& Tulving, 1997). Neuroimaging studies have also reported the activation of the MPFC during tasks involving self-processing, i.e. self-reflection, self-perspective and free thoughts. For instance, in the study of Gusnard et al. (2001), subjects had to make two judgements in response to pleasant versus unpleasant pictures (i.e. self-referential) and indoors versus outdoors pictures (i.e. not self-referential). The authors showed that the self-referential task was associated with activity along the dorsal MPFC. The MPFC was also selectively engaged when subjects had to make self-referential judgements about trait adjectives (i.e. self-referential processing) as compared to when they had to make case judgements (Kelley et al., 2002). The same region was involved when subjects responded to statements requiring knowledge of, and reflection on, their own abilities, traits and attitudes, i.e. self-reflective thought (Johnson et al., 2002). Taking a self-perspective (i.e. being the agent of an history) also activated MPFC (labelled by the authors anterior cingulate cortex $[x=6, y=54, z=-4]$ ) (Vogeley et al., 2001). At last, the activation of the MPFC was described in studies dealing with the conscious resting state, i.e. free thought (Mazoyer et al., 2001; Raichle et al., 2001), a brain state which "instantiates

\footnotetext{
${ }^{1}$ The present study allowed us to identify the brain structures which are modulated by the occurrence of the SON but not those which are responsible of the generation of the $\mathrm{P} 3$ wave.
} 
functions that are integral to the self" (Gusnard et al., 2001).

In our study, the hemodynamic response in the MPFC was more correlated to the P3 amplitude in the context of SON processing than by any other first name [significant (S20 + S50) versus (U20 + U50) by P3 interaction]. Thus, since one's own name is one of the most socially self related stimuli, this result suggests that MPFC seems involved in self-processing.

Second, a significant regression with P3 was observed in the right superior temporal sulcus, activated when subjects were asked to think intensely on how they would describe the personality traits and physical appearance of themselves (Kjaer et al., 2002). This region was also described when subjects read stories that induced a selfperspective (Vogeley et al., 2001). However, the involvement of this region in first-person perspective processing appears to be rather complex since the right temporo-parietal junction was also detected in thirdperson perspective processing, either motor (Ruby \& Decety, 2001) or conceptual — 'theory of mind' (Frith \& Frith, 1999; Ruby \& Decety, 2003). The apparent paradoxical involvement of the right temporo-parietal junction in both self and other processing suggests that this region is involved when subjects have to make a distinction between self and other but is not specific to one of the two processes.

Third, covariations between P3 amplitude and rCBF were observedinthe precuneus. Thisisconsistent with many previous neuroimaging studies on self-processing (self-reflection: Kircher et al., 2000, 2002; Kjaeret al., 2002, self-perspective: Vogeley et al., 2001 and free thoughts: Mazoyer et al., 2001; Raichle et al., 2001) and on thirdperson perspective (see, for example, Ruby \& Decety, 2001). In a broader perspective, this region seems to play a central role in the different states of consciousness. It is one of the most active cerebral regions in conscious waking (Andreasen et al., 1995) and one of the least active in states of altered consciousness. Indeed, rCBF decreases were observed in this region during paradoxical and slow-wave sleep (for a review, see Maquet, 2000), in vegetative state patients (Laureyset al., 1999), in the hypnotic state (Maquet et al., 1999) and in general anaesthesia (Alkire et al., 1999; Fiset et al., 1999; Kaisti et al., 2002). Thus, the modulation of consciousness associated to the modulation of activity in the precuneus suggests that this region participates in the neural network subserving conscious perception. The present paradigm does not permit to disentangle explicit from implicit detection of the SON; further researches should answer to this question.

At last, our results show a possible predominant role of the right hemisphere in self-processing. While previous work has also reported a right dominance related to activation of the superior temporal sulcus (Kjaer et al., 2002; Vogeley et al., 2001), results are inconsistent for the frontal cortex: some authors stipulated that the right prefrontal cortex may play a stronger role than the left in self processing (for example, Keenan et al., 2000), other claimed the opposite (for example, Turk et al., 2002). In our study, the right hemispheric dominance is probably linked to the emotional importance of the SON, in line with previous studies suggesting that the right hemisphere is determinant in emotion processing (see, for example, Adolphs et al., 1996; Schwartz et al., 1975).

In conclusion, the present study illustrates the interest of combining ERPs and PET scan methods, since the cerebral basis of the discrimination of the SON could be highlighted only by introducing the P3 covariate. Moreover, we demonstrated for the first time that the electrophysiological manifestations of the detection of one's own name, i.e. the P3 potential, correlate with neural activity measured in medial prefrontal cortex. Future studies could use this approach to evaluate the residual self-awareness in states of altered consciousness (i.e. coma, vegetative state, sleepor general anaesthesia).

\section{Acknowledgements}

The research has been supported by a Tom Slick Research Award, Mind Science Foundation, Texas, USA, the Fonds National de la Recherche Scientifique de Belgique (FNRS), the Fondation Médicale Reine Elisabeth (FMRE) and the Research Fund of the University Hospital CHU, Sart Tilman, Liège. Fabien Perrin was supported by the Fondation Fyssen and by Marie Curie Individual Fellowship, Philippe Peigneux by PAI/IAP P5/04 and Steven Laureys and Pierre Maquet are, respectively, Research Associate and Research Director at the FNRS. We thank C. Phillips, E. Salmon and S. Brédart for helpful comments and J. Hodiaumont, P. Hawotte and J.-L. Genon for technical assistance. 
Published in: Neuropsychologia (2005), vol. 43, iss. 1, pp. 12-19

Status : Postprint (Author's version)

\section{References}

Ackerly, S. S., \& Benton, A. L. (1947). Report of case of bilateral frontal lobe defect. Research Publications: Association for Research in Nervous and Mental Disease, 27, 479-504.

Adolphs, R., Damasio, H., Tranel, D., \& Damasio, A. R. (1996). Cortical systems for the recognition of emotion in facial expressions. Journal of Neuroscience, 16, 7678-7687.

Alkire, M. T., Pomfrett, C. J., Haier, R. J., Gianzero, M. V., Chan, C. M., Jacobsen, B. P., et al. (1999). Functional brain imaging during anesthesia in humans: Effects of halothane on global and regional cerebral glucose metabolism. Anesthesiology, 90, 701-709.

Andreasen, N. C., O’Leary, D. S., Cizadlo, T., Arndt, S., Rezai, K., Watkins, G. L., et al. (1995). Remembering the past: Two facets of episodic memory explored with positron emission tomography. American Journal of Psychiatry, 152, 1576-1585.

Berlad, I., \& Pratt, H. (1995). P300 in response to the subject's own name. Electroencephalography \& Clinical Neurophysiology, 96, 472474.

Damasio, A. R., Trenel, D., \& Damasio, H. (1990). Individuals with sociopathic behavior caused by frontal damage fail to respond autonomically to social stimuli. Behavioural Brain Research, 41, 81-94.

Fiset, P., Paus, T., Daloze, T., Plourde, G., Meuret, P., Bonhomme, V., et al. (1999). Brain mechanisms of propofol-induced loss of consciousness in humans: A positron emission tomographic study. Journal of Neuroscience, 19, 5506-5513.

Fishback, D. B. (1977). Mental status questionnaire for organic brain syndrome, with a new visual counting test. Journal of the American Geriatrics Society, 25, 167-170.

Folmer, R. L., \& Yingling, C. D. (1997). Auditory P3 responses to name stimuli. Brain \& Language, 56, $306-311$.

Frith, C. D., \& Frith, U. (1999). Interacting minds-A biological basis. Science, 286, 1692-1695.

Gallagher, S. (2000). Philosophical conceptions of the self: implications for cognitive science. Trends in Cognitive Sciences, 4, 14-21.

Gusnard, D. A., Akbudak, E., Shulman, G. L., \& Raichle, M. E. (2001). Medial prefrontal cortex and self-referential mental activity: Relation to a default mode of brain function. Proceedings in the National Academy of Sciences of the United States of America, 98,4259 4264.

Jasper, H. H. (1958). Report of the commitee on methods of clinical examination in electroencephalography. Electroencephalography \& Clinical Neurophysiology, 10, 370-375.

Johnson, S. C., Baxter, L. C., Wilder, L. S., Pipe, J. G., Heiserman, J. E., \& Prigatano, G. P. (2002). Neural correlates of self-reflection. Brain, 125, 1808-1814.

Kaisti, K. K., Metsahonkala, L., Teras, M., Oikonen, V., Aalto, S., Jaaskelainen, S., et al. (2002). Effects of surgical levels of propofol and sevoflurane anesthesia on cerebral blood flow in healthy subjects studied with positron emission tomography. Anesthesiology, 96, 13581370 .

Kelley, W. M., Macrae, C. N., Wyland, C. L., Caglar, S., Inati, S., \& Heartherton, T. F. (2002). Finding the self? An event-related fMRI study. Journal of Cognitive Neuroscience, 14, 785-794.

Keenan, J. P., Wheeler, M. A., Gallup, G. G., Jr., \& Pascual-Leone, A. (2000). Self-recognition and the right prefrontal cortex. Trends in Cognitive Sciences, 4, 338-344.

Kircher, T. T., Senior, C., Phillips, M. L., Benson, P. J., Bullmore, E. T., Brammer, M., et al. (2000). Towards a functional neuroanatomy of self processing: Effects of faces and words. Cognitive Brain Research, 10, 133-144.

Kircher, T. T., Senior, C., Phillips, M. L., Rabe-Hesketh, S., Benson, P. J., Bullmore, E. T., et al. (2001). Recognizing one's own face. Cognition, 78, B1-B15.

Kircher, T. T., Brammer, M., Bullmore, E. T., Simmons, A., Bartels, M., \& David, A. S. (2002). The neural correlates of intentional and incidental self-processing. Neuropsychologia, 40, 683-692.

Kircher, T. T., \& David, A. S. (2003). The self in neuroscience and psychiatry. Cambridge: Cambridge University Press.

Kjaer, T. W., Nowak, M., \& Lou, H. C. (2002). Reflective self-awareness and conscious states: PET evidence for a com-mon midline parietofrontal core. NeuroImage, 17, 1080-1086.

Klem, G. H., Lüders, H. O., Jasper, H. H., \& Elger, C. (1999). The ten-twenty electrode of the international federation. In G. Deuschl \& A. Eisen (Eds.), Recommendations for the practice of clinical neurophysiology: Guidelines of the international federation of clinical 
Published in: Neuropsychologia (2005), vol. 43, iss. 1, pp. 12-19

Status : Postprint (Author's version)

neurophysiology (pp. 3-6). Amsterdam: Elsevier.

Kurtz, D., Trapp, C., Kieny, M. T., Wassmer, J. M., Mugnaioni, M. D., Pack, A., et al. (1977). Study of recovery and the post-anaesthetic period. Revue d'Electroencephalographie \& Neurophysiologie Clinique, 7, 62-69.

Lane, R. D., Fink, G. R., Chau, P. M., \& Dolan, R. J. (1997). Neural activation during selective attention to subjective emotional responses. NeuroReport, 8, 3969-3972.

Laureys, S., Goldman, S., Phillips, C., Van Bogaert, P., Aerts, J., Luxen, A., et al. (1999). Impaired effective cortical connectivity in vegetative state: Preliminary investigation using PET. NeuroImage, 9, 377-382.

Mack, A., Pappas, Z., Silverman, M., \& Gay, R. (2002). What we see: Inattention and the capture of attention by meaning. Consciousness \& Cognition, 11, 488-506.

Mandel, D. R., Jusczyk, P. W., \& Pisoni, D. B. (1995). Infants' recognition of the sound patterns of their own names. Psychological Science, $6,314-317$.

Maquet, P., Faymonville, M. E., Degueldre, C., Delfiore, G., Franck, G., Luxen, A., et al. (1999). Functional neuroanatomy of hypnotic state. Biological Psychiatry, 45, 327-333.

Maquet, P. (2000). Functional neuroimaging of normal human sleep by positron emission tomography. Journal of Sleep Research, 9 , 207231.

Mazoyer, B., Zago, L., Mellet, E., Bricogne, S., Etard, O., Houde, O., et al. (2001). Cortical networks for working memory and executive functions sustain the conscious resting state in man. Brain Research Bulletin, 54, 287-298.

Moray, N. (1959). Attention in dichotic listening: Affective cues and the influence of instructions. Quarterly Journal of Experimental Psychology, 11, 56-60.

Oldfield, R. C. (1971). The assessment and analysis of handedness: The Edinburgh inventory. Neuropsychologia, 9, 97-113.

Oswald, I., Taylor, A. M., \& Treisman, M. (1960). Discriminative responses to stimulation during human sleep. Brain, 80, 440-453.

Perrin, F., García-Larrea, L., Mauguiere, F., \& Bastuji, H. (1999). A differential brain response to the subject's own name persists during sleep. Clinical Neurophysiology, 110, 2153-2164.

Perrin, F., Bastuji, H., Mauguiere, F., \& García-Larrea, L. (2000). Functional dissociation of the early and late portions of human Kcomplexes. NeuroReport, 11, 1637-1640.

Picton, T. W. (1992). The P300 wave of the human event-related potential. Journal of Clinical Neurophysioogy, 9, 456-479.

Pratt, H., Berlad, I., \& Lavie, P. (1999). 'Oddball' event-related potentials and information processing during REM and non-REM sleep. Clinical Neurophysiology, 110, 53-61.

Raichle, M. E., MacLeod, A. M., Snyder, A. Z., Powers, W. J., Gusnard, D. A., \& Shulman, G. L. (2001). A default mode of brain function. Proceedings in the National Academy of Sciences of the United States of America, 98, 676-682.

Ruby, P., \& Decety, J. (2001). Effect of subjective perspective taking during simulation of action: A PET investigation of agency. Nature Neuroscience, 4, 546-550.

Ruby, P., \& Decety, J. (2003). What do you believe versus what do you think they believe: A neuroimaging study of conceptual perspective taking. European Journal of Neuroscience, 17, 2475-2480.

Schwartz, G. E., Davidson, R. J., \& Maer, F. (1975). Right hemisphere lateralization for emotion in the human brain: Interactions with cognition. Science, 190, 286-288.

Signorino, M., D’Acunto, S., Angeleri, F., \& Pietropaoli, P. (1995). Eliciting P300 in comatose patients. Lancet, 345, $255-256$.

Stuss, D. T. (1991). Disturbance of self-awareness after frontal system damage. In G. P. Prigatano \& D. L. Schacter (Eds.), Awareness of deficit after brain injury: Clinical and theorical issues (pp. 63-83). New York: Oxford University Press.

Talairach, J., \& Tournoux, P. (1988). Co-planar stereotaxic atlas of the human brain 3-dimensional proportional system: An approach to cerebral imaging. Stuggart: Georg Thieme Verlag.

Turk, D. J., Heatherton, T. F., Kelley, W. M., Funnell, M. G., Gazzaniga, M. S., \& Macrae, C. N. (2002). Mike or me? Self-recognition in a split-brain patient. Nature Neuroscience, 5, 841-842.

Vogeley, K., Bussfeld, P., Newen, A., Herrmann, S., Happe, F., Falkai, P., et al. (2001). Mind reading: Neural mechanisms of theory of mind 
Published in: Neuropsychologia (2005), vol. 43, iss. 1, pp. 12-19

Status : Postprint (Author's version)

and self-perspective. NeuroImage, 14, 170-181.

Vogeley, K., \& Fink, G. R. (2003). Neural correlates of the first-person-perspective. Trends in Cognitive Sciences, 7, 38-42.

Wheeler, M. A., Stuss, D. T., \& Tulving, E. (1997). Toward a theory of episodic memory: The frontal lobes and autonoetic consciousness. Psychological Bulletin, 121, 331-354.

Wicker, B., Ruby, P., Royet, J. P., \& Fonlupt, P. (2003). A relation between rest and the self in the brain? Brain Research Review, 43, 224230 .

Wood, N., \& Cowan, N. (1995). The cocktail party phenomenon revisited: How frequent are attention shifts to one's name in an irrelevant auditory channel? Journal of Experimental Psychology: Learning, Memory \& Cognition, 21, 255-260. 